\title{
Erratum to: Information and Communication Technology and the Teacher of the Future
}

\author{
Carolyn Dowling ${ }^{1}$ and Kwok-Wing Lai ${ }^{2}$ \\ 1 Australian Catholic University, Australia \\ 2 University of Otago, New Zealand
}

\section{Erratum to: \\ C. Dowling and K.-W. Lai (Eds.) \\ Information and Communication Technology and the Teacher of the Future \\ DOI: $10.1007 / 978-0-387-35701-0$}

The book was inadvertently published with an incorrect name of the copyright holder. The name of the copyright holder for this book is: (c) IFIP International Federation for Information Processing. The book has been updated with the changes. 